\section{Commentary: Germ cell serum tumor markers: The canary in the coal mine?}

\author{
Valerie W. Rusch, MD
}

Primary mediastinal nonseminomatous germ cell tumors (PMNSGCTs) are rare malignancies that remain among the foremost multidisciplinary and technical challenges in thoracic oncology. In this issue of The Journal, Kesler and colleagues ${ }^{1}$ from Indiana University review their experience with the management of PMNSGCTs to identify prognostic factors and key aspects of surgical management.

The development of effective cisplatin-based chemotherapy regimens by Einhorn in the 1970s (known as the "Einhorn regimen") transformed metastatic testicular and PMNSGCTs from highly lethal to curable cancers. ${ }^{2,3}$ Since then, other institutions, including Memorial Sloan Kettering Cancer Center, have extended his pioneering work and made notable contributions to the management of PMNSGCTs. ${ }^{4,5}$

The extensive experience, careful follow-up, and 35 years of cumulative wisdom gained through the partnership of an expert medical oncologist and an expert thoracic surgeon make this study a landmark contribution to the published literature. Following initial chemotherapy, approximately $60 \%$ of patients experienced normalization of serum tumor markers (alpha-fetoprotein and beta human chorionic gonadotropin). Microscopically complete (R0) resections were achieved in all but 3 of 225 patients, including the $40 \%$ of patients who had persistent malignancy in the primary tumor site. Complete resection is the best treatment option in patients with active residual cancer or elevated preoperative tumor markers after chemotherapy, even

From the Thoracic Service, Department of Surgery, Memorial Sloan Kettering Cancer Center, New York, NY

Disclosure: Author has participated in institutional clinical trials funded by Genentech and Genelux. She is Co-Chair of the NIH Thoracic Malignancy Staging Committee and a member of the Data Safety and Monitoring Committee of the MARS2 trial

This work was supported in part by National Institutes of Health/National Cancer Institute Cancer Center Support Grant P30 CA008748.

Received for publication Feb 28, 2020; accepted for publication March 4, 2020; available ahead of print March 19, 2020.

Address for reprints: Valerie W. Rusch, MD, Memorial Sloan-Kettering Cancer Center, 1275 York Ave, New York, NY 10065 (E-mail: ruschv@mskcc.org).

J Thorac Cardiovasc Surg 2021;161:1961-2 $0022-5223 / \$ 36.00$

Copyright (c) 2020 Published by Elsevier Inc. on behalf of The American Association for Thoracic Surgery

https://doi.org/10.1016/j.jtcvs.2020.03.030

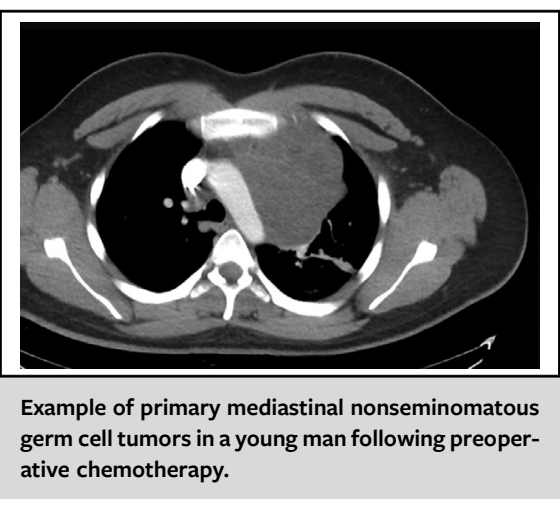

CENTRAL MESSAGE

Expert multidisciplinary care

guided by serum tumor markers and followed by complete surgi-

cal resection is central to suc-

cessful treatment of mediastinal

germ cell tumors.

though overall survival is not as favorable as in patients who have normalized tumor markers or residual mature teratoma. Additional second-line chemotherapy with stem cell transplantation preoperatively does not offer improved results. ${ }^{1,6}$ Multivariate analysis identified only preoperative histological subtype, residual active malignancy in the resected tumor, and elevated postoperative serum tumor markers as significantly predictive of poor overall survival. Effectively, elevated postoperative serum tumor markers were the proverbial "canary in the coal mine," a harbinger of subsequent recurrence.

Postoperative morbidity remains an important concern in this PMNSGCT population. In most patients, extended resections with removal of adjacent mediastinal organs or multiple operations are necessary to remove all disease. Preoperative bleomycin, historically used in these relatively chemoresistant tumors, poses a risk of postoperative acute respiratory distress syndrome, which in turn is fatal in approximately $40 \%$ of cases. The risk of acute respiratory distress syndrome can be mitigated by dose adjustment based on monitoring the diffusion and vital capacity on serial pulmonary function testing and by maintaining a low fraction of inspired oxygen intraoperatively. Regimens containing ifosfamide rather than bleomycin are associated with less pulmonary toxicity and should be used whenever possible. Coordinated multidisciplinary care by the medical 
oncologist, thoracic surgeon, and thoracic anesthesiologist is essential to minimizing pulmonary toxicity. ${ }^{4,5}$ The complex management suggest that patients with PMNSGCT are best cared for in centers of excellence.

Unfortunately, overall survival in PMNSGCT has remained static for decades at roughly $45 \%$ at 5 years. ${ }^{6}$ Clinical and pathological characteristics and serum tumor markers identify the patients at risk. Novel therapies are sorely needed, and hopefully the era of precision medicine can deliver these.

\section{References}

1. Kesler KA, Stram AR, Timsina LR, Turrentine MW, Brown JW, Einhorn LH Outcomes following surgery for primary mediastinal nonseminomatous germ cell tumors in the cisplatin era. J Thorac Cardiovasc Surg. 2021;161: 1947-59.e1.

2. Einhorn LH, Donohue JH. Cis-diamminedichloroplatinum, vinblastine, and bleomycin combination chemotherapy in disseminated testicular cancer. Ann Intern Med. 1977;87:293-8.

3. Rusch VW, Logothetis C, Samuels M. Endodermal sinus tumor of the mediastinum. Report of apparent cure in two patients with extensive disease. Chest. 1984;85:745-7.

4. Sarkaria IS, Bains MS, Sood S, Sima CS, Reuter VE, Flores RM, et al. Resection of primary mediastinal non-seminomatous germ cell tumors. A 28-year experience at Memorial Sloan-Kettering Cancer Center. J Thorac Oncol. 2011;6:1236-41.

5. Caso R, Jones GD, Bains MS, Hsu M, Tan KS, Feldman DR, et al. Outcomes after multidisciplinary management of primary mediastinal germ cell tumors. Ann Surg. January 21, 2020; https://doi.org/10.1097/SLA.0000000000003754 [Epub ahead of print].

6. Bokemeyer C, Nichols CR, Droz J-P, Schmoll H-J, Horwich A, Gerl A, et al. Extragonadal germ cell tumors of the mediastinum and retroperitoneum: results from an international analysis. J Clin Oncol. 2002;20:1864-73. 